\title{
Percepção de Integridade Científica para o Estudante de Medicina
}

\author{
Perception of Scientific Integrity by Medical \\ Students
}

\author{
Patrícia Dias Schmitz \\ Marta Menezes \\ Liliane Lins ${ }^{I I}$
}

\section{PALAVRAS-CHAVE}

- Revisão de Integridade Científica.

- Estudantes de Medicina.

- Má Conduta Científica.

- Educação Médica.

\section{KEYWORDS}

- Scientific Integrity Review.

- Medical Students.

- Scientific Misconduct.

- Medical Education.

Recebido em: 19/10/2011

Reencaminhado em: 15/08/2012

Aprovado em: 04/10/2012

REVISTA BRASILEIRA DE EDUCAÇ̄̃O MÉDic $447 \overline{36(4): 447455: 2012}$
${ }^{I}$ Escola Bahiana de Medicina e Saúde Pública, Salvador, Bahia, Brasil.

"I Escola Bahiana de Medicina e Saúde Pública; Universidade Federal da Bahia, Salvador, Bahia, Brasil. 


\section{INTRODUÇÃO}

Antes do século XX, a ausência de tecnologias que pudessem alterar de forma permanente a natureza fazia os cientistas se preocuparem apenas com a ética nas relações interpessoais ${ }^{1}$. No entanto, o surgimento da Bioética, na década de 1970, trouxe reflexões não somente a respeito do comportamento moral humano em relação à sua espécie em caráter imediato. Desta forma, o filósofo Hans Jonas amplia o conceito kantiano de que o homem deve ser um fim em si mesmo, para o exercício da Ética da responsabilidade com a preservação do planeta e as gerações futuras. A abordagem dos problemas éticos advindos dos avanços tecnológicos em seu livro "O princípio da responsabilidade: o ensaio de uma ética para civilização tecnológica"2, em 1979, apresenta a responsabilidade como fruto da consciência moral do pesquisador detentor do saber. Este indivíduo consciente tem o dever de agir em favor dos sujeitos da pesquisa, protegendo-os em sua vulnerabilidade e beneficiando-os, assim como deve zelar pela integridade científica na certeza de que suas ações têm consequências desde a microsfera à macrosfera social. Neste sentido, a desonestidade científica, seja no planejamento da pesquisa ou na execução da mesma, apresenta consequências graves na formação de pesquisadores, nas evidências científicas norteadoras de condutas clínicas, assim como nos gastos públicos com a realização de pesquisas.

A busca por prestígio, o poder das indústrias farmacêuticas e a pressão do sistema científico são alguns dos fatores que passaram a exigir maior atenção na questão da integridade científica $^{3}$. Esse novo termo remete a uma atitude pessoal e moral que pressupõe reflexões sobre ética, autocrítica e autodisciplina ${ }^{4}$. A necessidade de maior discussão sobre a integridade científica é uma demanda da evolução da ciência.

A preocupação com a prevenção da prática em pesquisa desonesta se consolidou com a criação do Office of Research Integritry (ORI), fundado em 1992 nos Estados Unidos com a finalidade de lidar com a questão da má condução científica ${ }^{3}$. Em março de 2005, o ORI relatou 133 casos de má conduta científica de 1994 a 2003. Desses casos, 53\% foram por falsificação de dados, $29 \%$ por fabricação de resultados, $36 \%$ por ações conjuntas de fabricação/falsificação, entre outras desonestidades ocorridas com menor frequência ${ }^{5}$. O alerta incentivou diversos países a criarem seus próprios meios de regulação por terem sido alertados sobre o tamanho do problema que estava escondido até então. Em 1997, foi criado no Reino Unido o Comitê de Ética em Publicações (Committee on Publication Ethics - Cope) por um pequeno grupo de editores de revistas médicas, para combater as más condutas em pesquisas ${ }^{3}$. A instituição presta assessoria a editores em todos os aspectos da ética em publicação e, em particular, aconselha formas de lidar com casos de investigação e má conduta científica. Todos os seus membros, editoras bem conceituadas em todo o mundo, devem seguir um código de conduta próprio do comitê. Têm também o papel de ajudar na luta do Reino Unido pela integridade científica, assim como apoiar os encontros mundiais sobre o assunto ${ }^{6}$.

No Brasil, a publicação da Resolução nº 196 de 1996 pelo Conselho Nacional de Saúde (CNS) foi o marco do desenvolvimento da ideia de preservação da integridade dos seres humanos envolvidos na pesquisa e atribui ao Comitê de Ética e Pesquisa (CEP) a responsabilidade de acompanhar o desenvolvimento de projetos e requerer sindicâncias em caso de denúncias de irregularidades ${ }^{7.8}$. Esta Resolução estabelece a criação da Comissão Nacional de Ética em Pesquisa (Conep) e a associação do CEP a esta, fornecendo ao País uma discussão maior sobre a ética nos meios educacionais e maior prestígio para o Brasil em relação à produção científica internacional ${ }^{1}$. No entanto, o sistema é ineficaz no policiamento quanto à integridade da pesquisa, devendo este procedimento ser realizado pelos próprios pesquisadores e instituições de pesquisas.

Na realidade brasileira são presentes denúncias de grupos de fabricação e venda de teses e dissertações, alimentando publicações e titulações de pós-graduandos ${ }^{5}$, currículos com inclusão indevida de manuscritos e plágio eletrônico explícitos em trabalhos acadêmicos que apresentam variações de linguagem em seu contexto ${ }^{3}$. Outros problemas enfrentados por editores são: envio do mesmo artigo para dois periódicos distintos, o que caracteriza a transferência de direitos autorais de publicação para dois editores diferentes ${ }^{9}$, divisão dos resultados de um trabalho em vários artigos para obtenção de múltiplas publicações, e o autoplágio, reconhecido quando um autor cita sua frase em dois artigos sem fazer referência ao trabalho que foi publicado primeiro ${ }^{10}$. Estes são exemplos de má conduta científica que talvez pudessem ser evitados com maior educação sobre o assunto. Desta forma, o ensino da Ética aplicada à pesquisa deve proporcionar a abordagem de exemplos teóricos e práticos sobre o que é propriedade intelectual, direitos autorais e plágio em sala de aula por meio de técnicas andragógicas ${ }^{3}$.

É importante salientar que, no Brasil, ainda não há um órgão responsável por identificar a desonestidade científica e estabelecer sanções para coibir os atos eticamente inadequados, embora tenha sido criada em maio de 2011 uma Comissão do $\mathrm{CNPq}$, constituída por cientistas de grande experiência, que tem por objetivo propor diretrizes para a prática da honestidade na ciência. Um relatório dessa comissão divulgado em outubro de 2011 mostrou interesse em desestimular práticas desonestas, inclusive com ações punitivas, e estimular práticas preventivas, como as educacionais ${ }^{11}$. No entanto, esse documento ainda tem pouca repercussão entre os pesquisadores. Como consequência, não se conhece a dimensão deste problema no País ${ }^{12}$. 
A incerteza sobre se há ou não honestidade em determinada pesquisa pode prejudicar seriamente a reputação de alguns autores, assim como o entendimento de novas ideias, e a aplicação destas na prática estaria ameaçada. Os resultados das práticas eticamente inadequadas trazem muitas consequências, dentre as quais se encontram o mau uso de dinheiro público e o mau emprego de recursos humanos, e colocam a vida de seres humanos em risco, uma vez que os resultados forjados, principalmente na área médica, podem ser levados à prática ${ }^{12}$.

Embora exista uma tendência a responsabilizar o poder público pela falta de interesse em investigar e coibir a má conduta científica, as instituições de ensino, na condição de formadoras de futuros cientistas, por si só, devem se preocupar em transmitir aos estudantes a importância de exercer essa prática com honestidade ${ }^{3}$, demonstrando as grandes implicações negativas econômicas e morais que o plágio e a fraude, dentre outras condutas, podem ocasionar ao Brasil. Os professores também devem assumir uma postura de compromisso com a honestidade científica, servindo, assim, de exemplo.

Em setembro de 2011, a diretoria científica da Fundação de Amparo à Pesquisa do Estado de São Paulo (Fapesp) ${ }^{13}$ lançou um código de boas práticas para aconselhamento de todas as pessoas envolvidas em ciência. Essas normas têm como objetivo definir a integridade científica, para que todo pesquisador possa exercer sua profissão de maneira apropriada, contribuindo da melhor forma para o avanço da ciência. A instituição também se comprometeu a promover ações educativas destinadas a disseminar os valores de integridade científica e a conduzir ações independentes para investigar denúncias de má conduta. Essas ações representam um primeiro passo para conduzir as pesquisas em conformidade com os padrões internacionais de credibilidade científica, porém ainda são um passo inicial e localizado 20 anos após a criação do ORI nos Estados Unidos.

O presente artigo tem como objetivo conhecer a percepção de estudantes de Medicina sobre integridade científica e a preocupação com o desenvolvimento de medidas educativas que contribuam para a formar pesquisadores eticamente responsáveis. Por meio deste trabalho, poderá também ser obtido um diagnóstico de como se encontra o coletivo de pensamento acadêmico em relação à ética científica, possibilitando ações educacionais preventivas da má prática científica.

\section{MÉTODOS}

Foi realizado um estudo de corte transversal, descritivo e exploratório. Foi feita uma abordagem qualitativa mediante entrevista semiestruturada, utilizando-se a técnica de análise temática, por meio da qual se procurou entender a percepção dos estudantes de Medicina quanto à integridade científica. A casuística foi constituída de 20 estudantes distribuídos equitativamente entre o primeiro e o décimo semestre de um curso de Medicina na cidade de Salvador (BA). As entrevistas foram realizadas de julho a setembro de 2011 . O projeto de pesquisa, no 093/2011, foi aprovado pelo Comitê de Ética e Pesquisa da Escola Bahiana de Medicina e Saúde Pública, e os alunos que participaram assinaram um termo de consentimento livre e esclarecido. A saturação teórica foi o instrumento utilizado para determinar o número da população em estudo.

As entrevistas foram realizadas em local reservado, gravadas em fitas magnéticas e posteriormente transcritas em sua totalidade. Após a análise, foram arquivadas no Núcleo de Estudo e Pesquisa em Ética e Bioética da Escola Bahiana de Medicina e Saúde Pública.

Os alunos, inicialmente, responderam uma ficha de identificação com informações sobre idade, sexo, o semestre que estavam cursando e se já haviam realizado algum trabalho científico. Essa ficha tinha o propósito de alertar para uma possível interferência do curso ou de experiências pessoais nas respostas do aluno. A abordagem foi semidirigida, como descrita por Fontanella et al. ${ }^{14}$, com o objetivo de compreender o ponto de vista dos estudantes sobre o tema abordado, o que só pôde ser alcançado com o uso de um método que permitisse a livre expressão do participante.

Para análise do conteúdo das entrevistas foi utilizada a técnica qualitativa de análise temática ${ }^{15}$, formulada em três etapas: pré-análise, exploração do material e interpretação dos resultados obtidos, de acordo com o descrito a seguir.

A pré-análise foi dividida em leitura flutuante, definida pela leitura intensa do material; em constituição do corpus, onde o universo estudado alcança exaustividade, representatividade, homogeneidade e pertinência; e em formulação de hipóteses e objetivos, onde ocorreu a retomada da primeira etapa exploratória com reformulação de hipóteses para que a riqueza do material de pesquisa não seja obscurecida pelo tecnicismo ${ }^{15}$. A exploração do material consistiu na classificação das unidades temáticas, visando alcançar melhor compreensão dos resultados. $\mathrm{Na}$ interpretação dos resultados, última etapa, foi verificada a frequência dos mesmos, o que permitiu colocar em relevo as informações obtidas, propiciando melhor esclarecimento e desenvolvimento temático.

\section{RESULTADOS E DISCUSSÃO}

\section{Amostra}

Inicialmente, a amostragem teórica constituía-se de 16 estudantes distribuídos equitativamente entre o primeiro e o oitavo semestre de um curso de Medicina. No entanto, devido ao surgimento de novas categorias temáticas durante a análise de 
conteúdo, percebeu-se a importância de ampliar a amostra até que se obtivesse a saturação teórica com 20 alunos divididos entre o primeiro e o décimo semestre da faculdade pesquisada. Dessa amostra, 12 estudantes eram do sexo feminino (60\%) e 8 do sexo masculino (40\%). A média de idade foi de 21,3 $\pm 2,05$ anos, com amplitude de 18 a 25 anos. Em relação às matérias cursadas, os 20 alunos (100\%) da amostra já haviam concluído a disciplina modular Metodologia em Pesquisa, 18 alunos (90\%) já haviam passado pelo componente curricular Ética e Bioética, 10 alunos (50\%) já cursaram ou estão cursando os componentes curriculares de raciocínio clínico baseado em evidência e elementos da metodologia epidemiológica e comunicação científica, e ainda 6 alunos (6\%) haviam realizado o trabalho de conclusão de curso e cumprido carga horária na matéria de Metodologia da Pesquisa Clínica e Medicina Interna.

\section{Categorização do material}

Foram definidas três unidades de análise dos dados:

- Conhecimento do estudante sobre o sistema CEP/Conep;

- Percepção dos estudantes sobre integridade científica e desonestidade científica;

- Abordagem do tema integridade científica no currículo médico.

\section{Conhecimento dos estudantes sobre o CEP e a Conep}

Observou-se que dos 20 estudantes entrevistados apenas 4 (20\%) sabiam o significado da sigla Conep. Foi evidenciada pouca associação dos termos Conep e CEP com as funções atribuídas a estes órgãos regulatórios em pesquisa. Dos 11 estudantes que não sabiam o significado do CEP, 9 (81,8\%) já haviam passado pela matéria Ética e Bioética na faculdade e todos já haviam cursado a matéria de Metodologia em Pesquisa. Somente $5(25 \%)$ estudantes de toda a amostra tinham conhecimento de que o Comitê de Ética em Pesquisa tem a função de avaliar os projetos que envolvem seres humanos com o objetivo de analisar se os mesmos atendem aos princípios básicos da Bioética, como autonomia, não maleficência, beneficência e justiça, assim como às normas legais do País. Ao serem indagados sobre quais trabalhos deveriam ser enviados ao comitê para aprovação, 7 $(35 \%)$ responderam corretamente. O erro mais comum entre os estudantes foi achar que trabalhos que envolvem animais devem também ser submetidos ao CEP, mostrando desconhecimento do Comitê de Ética no Uso de Animais (Ceua). Algumas dessas narrativas podem ser observadas a seguir:

"O CEP serve para termos um controle com animais, experimentos e pesquisas. Com pessoas também." (M09)
"Eu acho que eles avaliam o que você vai utilizar no seu projeto com animais [...] para evitar sacrifícios desnecessários ou então falta de ética com a pesquisa. Eu fiz um projeto que envolvia animais, então a única coisa que eu sei do comitê é isso." (M12)

"Quando você vai trabalhar com humanos ou com animais, você tem que ter um controle, mas eu não sei direito como é não." (M14)

"Qualquer trabalho que envolva humanos ou animais tem que ser mandado para o CEP." (M19)

"Se você faz um projeto de pesquisa e envolve tanto humanos quanto animais [...] você tem que fazer o projeto certo e tem que passar pelo CEP [...]" (M20)

A pesquisa detectou outros exemplos que denotam confusão a respeito das funções do sistema CEP/Conep. Dentre esses, achar que só trabalhos na área de Medicina deveriam ser enviados ao CEP ou que todos os trabalhos, inclusive as revisões bibliográficas, deveriam ser analisados por este sistema. Ainda, alguns estudantes pensavam que o CEP constitui uma auditoria médica que fiscaliza más condutas, como a quebra de sigilo médico e negligência terapêutica.

Foi na revisão da Declaração de Helsinque, em 1975, em Tóquio, que se falou pela primeira vez da importância da instituição de um comitê que pudesse regular eticamente a produção científica com envolvimento de seres humanos. Essa necessidade se manteve inalterada nas revisões seguintes da Declaração, evidenciando a necessidade do respeito a exigências éticas, legais e regulatórias no processo de desenvolvimento do estudo científico ${ }^{16}$. A ética e a metodologia do estudo devem ter vínculo indissociável, por isso devem ser abordadas abundantemente nas instituições de pesquisa, assim como nas de fomento à mesma. As Diretrizes Éticas Internacionais para a Pesquisa Biomédica em Seres Humanos, inicialmente publicadas em 1982, apontam a importância do respeito à proteção dos sujeitos das pesquisas e afirmam que a pesquisa só pode se justificar eticamente se a sua expectativa for a de beneficiar as pessoas $^{17}$. Portanto, se os pesquisadores não estiverem engajados nas questões éticas relativas à produção da ciência, em prol do benefício dos seres humanos, dificilmente irá se obter um estudo de impacto para a comunidade ${ }^{18}$.

\section{Percepção dos estudantes sobre integridade e desonestidade científica}

A expressão integridade científica emergiu nos últimos anos no meio científico como um tópico polêmico sobre a conduta dos pesquisadores e tem sido cada vez mais abordada em ní- 
vel mundial ${ }^{19}$. A integridade científica remete aos valores que se impõem ao cientista em virtude de seu compromisso com a finalidade de sua profissão, que seria a construção coletiva da ciência como patrimônio coletivo. Portanto, o pesquisador deve se abster de agir, intencionalmente ou por negligência, de modo a impedir ou prejudicar o trabalho coletivo de construção da ciência ou apropriação coletiva de seus resultados ${ }^{13}$.

As instituições que promovem pesquisas ou que levantam fundos para a pesquisa têm como uma de suas responsabilidades formar pesquisadores íntegros, de acordo com o Guidelines for Scientific Integrity, do Scientific Integrity Committee of Midwest Nursing Research Society, publicado parcialmente em português em forma de resenha, o que revela a preocupação de profissionais da área de saúde com a produção da ciência. No Brasil, embora tenha havido progressos quanto à ética relacionada à pesquisa com a criação do Conep, em 1996, e dos CEPs, em diversas instituições, permanecem ainda pouco exploradas questões de integridade na tramitação de projetos e relatórios de pesquisa em seus diversos níveis, desde os órgãos de fomento, às universidades e aos conselhos editoriais ${ }^{20}$.

No âmbito acadêmico de graduação, este fato pode ser observado quando os relatos dos discentes são analisados. Somente 5 alunos (25\%) tinham ouvido falar do termo integridade científica, mas nenhum sabia o que ele significava em seu contexto global, apesar de 11 (55\%) dos entrevistados já terem realizado algum trabalho científico. Pudemos perceber relatos como:

\begin{abstract}
"A integridade científica [...] não sei, talvez seja alguma coisa relacionada a você não olhar somente pelo lado científico, mas também tratar a pessoa de uma forma mais humanitária." (M12)
\end{abstract}

“Já ouvi falar, mas não sei o que é." (M16)

“É uma comunhão de toda a comunidade científica [...] tenho que mandar a minha pesquisa para algum órgão para que ele avalie se tem alguma disfunção." (M17)

“[...] Eu não sei. Mas se eu pensar literalmente sobre o nome, eu acho que são trabalhos dentro dos parâmetros do comitê de ética." (M20)

Dos estudantes que já ouviram falar sobre o termo integridade científica, a maioria o associou com a proteção do sujeito da pesquisa. Nenhum dos estudantes relacionou o termo com o processo de elaboração do projeto de pesquisa, ou com a necessidade de realização da pequisa para atender a demandas necessárias da humanidade, ou com a responsabilidade no uso adequado de recursos públicos e publicação dos dados, que podem, quando, plagiados, falsificados ou fabricados, causar sérios danos à sociedade, compreendendo o cidadão que paga impostos, os sujeitos da pesquisa e pesquisadores. De igual forma, a obrigação de publicação da pesquisa, sobretudo das financiadas com recursos públicos, não foi associada com integridade científica.

Outra questão abordada nesse mesmo tópico foi a percepção dos estudantes sobre a desonestidade científica. De acordo com um relatório sobre Integridade Ética na Pesquisa publicado pela Fapesp, para que um trabalho científico seja viável, é necessário que a comunidade científica tenha regras condutoras preestabelecidas e que estas possam promover a reputação na ciência de forma que os próprios pesquisadores exerçam um controle social responsável no intuito de coibir atos de transgressão. Desta forma, pesquisadores desonestos serão vistos como ameaçadores ao avanço da ciência, já que este ocorre e se move como consequência de sua credibilidade. Exemplos de transgressão dessas normas são chamados de má conduta científica, e nos órgãos internacionais esta é classificada em diferentes níveis. Dentre as más condutas graves se encontram: a fabricação, quando ocorre a invenção de dados, e a falsificação, definida pela manipulação intencional de dados. Outros exemplos são: plágio, atribuição incorreta de autoria, autoplágio, ocultação de conflitos de interesse, conservação inadequada dos registros de pesquisa e omissão de dados ${ }^{13}$. Dos exemplos de desonestidade citados pelos estudantes, percebemos que 5 (25\%) citaram o plágio, 7 (35\%) estudantes citaram a prática de ferir a dignidade de humanos e animais, e 7 (35\%) abordaram a fabricação de dados; em menor proporção, foram citadas a não randomização de dados, a autoria indevida, não fidelidade ao projeto e realização da pesquisa sem autorização do CEP. Estes resultados podem ser observados em alguns dos relatos a seguir:

\begin{abstract}
“É muito mais fácil você se valer do 'jeitinho'; por exemplo, você está fazendo uma pesquisa sobre a opinião do paciente e aí você chega em casa e muda o que ele respondeu para ter o resultado esperado, principalmente em pesquisas subjetivas." (M10)
\end{abstract}

“Desonestidade científica é você dizer ao paciente uma coisa e fazer outra, você revelar a identidade dele por exemplo." (M15)

“Eu já vi alguém que plagiou a pessoa que corrigiu a monografia dela." (M19)

Foi interessante notar que $80 \%$ dos estudantes já haviam presenciado plágio e $65 \%$ já presenciaram autoria indevida no ambiente acadêmico. No entanto, só $25 \%$ e $5 \%$ dos acadêmicos citaram o plágio e a autoria indevida, respectivamente, como 
exemplo de má conduta científica. Estes resultados demonstram que tais práticas são prevalentes, mas existe a necessidade de conscientização moral sobre boas condutas científicas.

A Associação Mundial de Editores de Revistas médicas define o plágio como o uso de publicações, ideias ou palavras sem a devida permissão ou sem atribuir os devidos créditos ao autor ${ }^{21}$. Este tema, apesar de conhecido no meio acadêmico, pois cerca de $85 \%$ dos estudantes sabiam definir o plágio, parece não ser abordado de forma eficaz. A educação apropriada para que esse tipo de prática não ocorra talvez esteja sendo insuficiente ou é possível que não haja o reconhecimento do grande prejuízo que a desonestidade científica pode causar. O plágio de resultados, particularmente em estudos de caso controle, pode afetar negativamente a prática médica, dando a falsa impressão de que uma conduta foi eficaz em mais de uma vez, dando uma confiança equivocada aos médicos que adotam tal resultado em sua rotina ${ }^{22}$. Os relatos a seguir denotam a prática do plágio no meio acadêmico:

"Eu já vi alunos pegando trabalhos de outros e depois de fazer pequenas modificações entregaram ao professor, mas até que ponto isso é plágio eu não sei." (M14)

“[...] Quando estava pesquisando na internet, encontrei frases idênticas aos trabalhos apresentados pelos meus colegas e eles não haviam botado referência. Mas não sei se isso é tão grave [...]" (M16)

"Eu acho que isso [o plágio] é uma prática comum, mas talvez o plágio não seja tão marginal, né? Por exemplo, a gente tem o trabalho de Metodologia [...] só que todo mundo vai olhar logo os trabalhos do semestre passado para copiar." (M17)

As citações refletem a insegurança do estudante sobre um tema prevalente e que remete à caracterização da desonestidade científica no meio acadêmico. A conscientização sobre as diferentes práticas de desonestidade na ciência é essencial para que o indivíduo reconheça que é detentor de uma natureza humana com virtudes e defeitos. Sem esta conscientização é inviável a prática científica de forma honesta.

Embora a elaboração da monografia de conclusão de curso, por seu caráter prático, esteja associada à maior assimilação da ética em pesquisa, existem estudantes que ainda assim praticam atos desonestos na realização da mesma. Este fato evidencia que esse ensino prático sobre boa conduta em ciência não deve ser responsabilidade única desse integrante curricular, assim como demonstra a necessidade de inserção pre- coce no curso médico de atividades práticas que objetivem a integridade científica. O relato a seguir evidencia este aspecto:

“Eu vi várias histórias de plágio na faculdade, inclusive na monografia, uma menina que pegou dois artigos e intercalou os parágrafos e entregou como trabalho de conclusão de curso." (M18)

Nenhum estudante ouviu falar em autoplágio, e apenas dois $(10 \%)$ sabiam que não se pode publicar o mesmo artigo em duas revistas diferentes. Os acadêmicos desconheciam também as regras sobre direitos autorais.

A autoria indevida é o segundo tipo de má conduta científica mais prevalente na faculdade de acordo com os discentes e nem sempre este ato desonesto é reconhecido por eles. Entre os motivos que geraram uma autoria indevida, o principal foi a preocupação em favorecer o colega. Alguns alunos informaram ter presenciado trabalhos com autores que não participaram da investigação científica, mas que, por serem renomados na área do trabalho, dariam a ele maior prestígio, possibilitando publicação de maior impacto. Foi observado também que somente seis alunos (30\%) sabiam as funções do autor de um trabalho. Recentemente este conceito foi abordado em uma publicação da Fapesp ${ }^{23}$, na qual se pressupõe que toda ideia e formulação verbal, orais ou escritas, sejam contribuição original dos pesquisadores indicados como autores de um trabalho. Além disso, os autores devem participar de todas as etapas do trabalho científico, desde a elaboração do projeto à revisão científica.

O conflito de interesse foi reconhecido por 35\% dos alunos, mas nenhum deles associou essa prática à desonestidade científica. O conflito de interesse ocorre quando o pesquisador pode ser influenciado por interesses secundários, como o de se beneficiar de informações, tecnologias, relações - pessoais ou institucionais -, equipamentos ou fundos, em detrimento da contribuição à ciência, com exercício da integridade, assim como da proteção dos interesses dos pacientes ${ }^{20}$. O erro mais comum entre os estudantes foi achar que esse termo remete a desentendimentos entre os autores de uma mesma pesquisa:

“[...] Deve estar relacionado à desorganização do grupo de pesquisa de pessoas que não se conhecem há muito tempo e se juntaram só em prol da pesquisa." (M17)

"[...] Ocorre quando o pesquisador usa os dados para provar algo que vai de encontro às ideias de determinado grupo." (M09)

"[...] O conflito de interesse ocorre quando você está defendendo um ponto de vista e existem outros pesquisadores defendendo outras áreas e vocês não entram em acordo." (M08) 
"O conflito de interesse ocorre quando uma pessoa quer fazer algo e a outra não quer, aí dá um conflito de interesse." (M06)

"O conflito de interesse ocorre quando existem dois lados e há uma divergência." (M05)

\section{Abordagem do tema integridade científica no currículo médico}

Dezoito estudantes (90\%) da amostra classificaram a discussão do tema integridade científica como insuficiente no meio acadêmico. Além disso, os estudantes demonstraram que a prática desonesta da ciência é comum nas universidades, como abordado no tópico anterior. Dos 2 (10\%) estudantes que acharam que o tema já é suficientemente abordado, 1 (50\%) não sabia o que significava plágio e nenhum sabia quais as funções do autor de um trabalho. Esse resultado alerta para a seguinte questão: existe a necessidade de inserção precoce de práticas andragógicas sobre o tema no currículo médico, pois, se os discentes não reconhecem as más práticas como desonestidade científica, eles poderão praticá-las devido à desinformação.

É importante refletir que o principal recurso contra a má conduta científica é a formação de uma cultura da integridade, ou seja, inserir certos valores na prática cotidiana a tal ponto que o respeito ocorra de forma espontânea e o desrespeito seja capaz de produzir reação imediata de reprovação pela comunidade científica ${ }^{13}$. Por isso, a educação para a promoção da boa ciência é tão importante, e essa percepção já podia ser observada no relato de alguns estudantes no início de sua atividade científica ao afirmarem que a maior abordagem desse assunto no meio acadêmico deve ser efetivada:

“[...] Durante a entrevista, a gente falou sobre vários assuntos que na faculdade não se discute [...] Acho importante falar sobre isso principalmente para preparar os alunos, porque a gente vai sair daqui sem saber ler um artigo com visão crítica." (M04)

“Eu nunca tinha ouvido nada sobre esse assunto [...] Eu acho que esse tema tem que ser mais bem abordado, pois hoje vivemos com muitos problemas em pesquisa, com o plágio, o envolvimento de dinheiro com as indústrias farmacêuticas [...]" (M05)

“É necessário discutir sobre o assunto, já que no Brasil temos muitos casos de corrupção, e a gente tem que barrar isso agora. Já na faculdade fica todo mundo plagiando, cada um tem que fazer sua parte." (M06)

Noventa por cento dos alunos afirmaram não saber avaliar os métodos de um trabalho científico e seus resultados quanto a sua fidelidade à ética e, portanto, procuram acreditar em trabalhos que são indicados por professores ou que lhes pareçam justos. Os relatos a seguir evidenciam estes aspectos:

$$
\begin{aligned}
& \text { “Eu apenas olho onde o artigo foi publicado." (M01) } \\
& \text { “Quando eu começo a ler e gosto do artigo, eu termino } \\
& \text { de ler." (M02) } \\
& \text { "Se eu estiver lendo uma revista que seja renomada, eu } \\
& \text { não me preocupo com a validade do artigo." (M05) } \\
& \text { "Eu confio em artigos que são publicados em universi- } \\
& \text { dades." (M06) }
\end{aligned}
$$

Cabe salientar que muitos trabalhos são citados sem conhecimento de que foram retratados cientificamente. $\mathrm{O}$ artigo publicado por Farthing ${ }^{24}$ evidenciou que, de 1966 a 1997, 235 artigos foram retratados, sendo os mesmos citados mais de 2 mil vezes. No entanto, somente $6 \%$ dessas citações tinham conhecimento de que os trabalhos tinham comprometimento em sua integridade científica. Estudos como o do pesquisador canadense Eric Poehlman, o primeiro cientista a ser preso por má conduta científica e que fabricou dados em vários estudos, inclusive sobre reposição hormonal em mulheres, continuam a influenciar a prática médica ${ }^{25}$. De igual forma, o biólogo sul coreano Hwang Woo-suk, famoso por anunciar ao mundo a realização de clonagem humana e desenvolvimento de diferentes linhagens de células-tronco, foi suspenso da comunidade científica por ter falsificado tais trabalhos, publicados inclusive na Science. Somando-se aos riscos de associação de pesquisas falsificadas à prática médica, muitos recursos foram investidos nessa pesquisa, mostrando o quão dispendiosa pode ser uma prática desonesta ${ }^{26}$. Talvez a frequente exaltação pública de resultados de pesquisa, a atenção continuada aos currículos e as pressões por publicação tenham causado essa conduta $^{5}$. Além disso, essa situação ilustra que não é só porque o autor é renomado ou a revista é séria que não ocorrem plágios, fabricação de resultados ou falsificação de dados. Portanto, os estudantes precisam ser instruídos adequadamente para a análise de um artigo científico de qualidade.

Os professores têm grande responsabilidade no processo de aprendizagem, e suas condutas acabam sendo incorporadas pelos estudantes como elemento de aprendizado. Dos estudantes pesquisados, 3 (15\%) relataram que em suas vivências acadêmicas já observaram más práticas por parte dos docentes. Dentre os exemplos citados um foi de plágio:

"Tem um professor nosso que pega os slides de outro professor que ele não conhece para apresentar as aulas. 
Nas referências ele coloca todos os livros, mas as informações nunca estão nos livros que ele diz." (M10)

Os outros dois exemplos ocorreram por orientação inadequada:

"Em um grupo de pesquisa associado à faculdade, os alunos captam os dados, que são bem complexos, e os autores nunca conferem." (M18)

"O professor que vai me orientar na monografia já começou logo falando que a gente vai publicar o trabalho, mas ele é que vai ser o autor principal. Eu me senti impotente, não pude dizer nada." (M07)

Pesquisadores em formação, seja de graduação ou pós-graduação, devem aprender a fazer pesquisa científica sob a orientação ou supervisão de pesquisadores devidamente qualificados. Pressupõe-se que o orientador aja em benefício da formação do discente como pesquisador independente. A utilização do aluno como mão de obra barata constitui uma conduta eticamente reprovável ${ }^{13}$.

Analisando os dados obtidos, em geral, pode-se observar que, após cursarem as matérias que tratam de Epidemiologia e Metodologia da Pesquisa, os alunos foram estimulados à prática da produção científica e apresentaram respostas mais consistentes pelo menos sobre a produção da pesquisa eticamente responsável com a dignidade humana. No entanto, a falta de melhor abordagem do tema ou de estímulo de prática precoce faz com que alguns alunos se sintam pressionados pelo tempo e pelas dificuldades metodológicas na produção da ciência e às vezes deem menor importância à ética na pesquisa. Alguns chegam a afirmar que se sentem estimulados a inventar os resultados para cumprir o tempo de entrega dos trabalhos de conclusão de curso. Outros não são devidamente instruídos e se desestimulam a seguir carreira científica, pela má experiência que lhes é imposta:

“Eu acho que ocorre a desonestidade científica por causa da nossa inexperiência em realizar trabalhos científicos. Se hoje eu tiver que fazer um artigo, eu vou ter um trabalhão simplesmente porque eu não sei fazer." (M11)

“Tem algo superirresponsável que acontece, a gente tem que escrever um artigo no segundo semestre sem nunca ter aprendido a fazer isso." (M17)

"Eu tenho a sensação de que vou me formar sem saber se na minha prática clínica vou ser correta, pois não sei avaliar vieses em pesquisa, e isso afeta diretamente minha conduta médica." (M18)
"Eu acho importante falar nesse tema porque às vezes as pessoas, por ignorância, acham que estão fazendo certo quando não é. Algumas coisas são meio óbvias, mas conflito de interesse, viés de pesquisa, eu acho que muitos fazem sem perceber que estão cometendo." (M19)

É necessário reavaliar a forma como a prática da ciência está sendo abordada no curso médico e a possibilidade de inseri-la precocemente na vida dos futuros pesquisadores. A integridade científica precisa estar atrelada a todas as etapas de aprendizado da ciência. A distinção entre boas e más condutas científicas é fundamental neste processo de aprendizado, exigindo, além de bom senso, competência científica, integridade e honestidade por parte dos pesquisadores em sua formação moral. Portanto, ao ser educador de um cientista em formação, o pesquisador deve ter responsabilidade em todo o processo, dispondo de tempo e competência científica. Os conceitos e as implicações da boa prática da ciência devem ser também mais bem discutidos entre os professores, para que estes possam dar o exemplo e ensinar de forma mais eficaz sobre essa prática inerente à qualidade da ciência.

\section{CONCLUSÃO}

Ao término deste trabalho, foi possível concluir que existe a necessidade de educação dos discentes sobre o sistema CEP/ Conep, assim como sobre as Resoluções que regulamentam a pesquisa no País.

O tema integridade científica para a formação de futuros médicos e pesquisadores é pouco discutido no meio acadêmico, o que pode gerar a prática de condutas inadequadas na produção científica por falta de reconhecimento das mesmas pelos discentes.

É preciso associar teoria e prática para o ensino da integridade científica, devendo o tema ser inserido precocemente no currículo médico.

\section{REFERÊNCIAS}

1. Azevedo ES. Desafios da bioética no século XXI. Gaz. méd. Bahia. 2008;78(1): 37-40.

2. Jonas H. Das prinzip verantwortung: versuch einer ethic für die technologische zivilisation. Frankfurt: am Main; 1979.

3. Azevedo ES. Honestidade Científica: Outro Desafio ao Controle da Ciência. Gaz. Médica da Bahia. 2006; 76 (1):35-41.

4. Bossi E. Scientific Integrity, misconduct in science. Swiss Med. Wkly.2010;140(13/14):183-86.

5. Azevedo ES. Integridade Científica. Como anda o Brasil? Jornal da Ciência [online]. 2005; 2779 [capturado em 18 out. 2011]. Disponível em: http://www.jornaldaciencia. org.br/Detalhe.jsp?id=28576. 
6. Smith R. The need for a national body for research misconduct, nothing less will reassure public. BMJ. 1998; 316(1686):1695-755.

7. Tavares-Neto J, Azevedo ES. Destaques éticos nos periódicos nacionais das áreas médicas. Rev. Assoc. Med. Bras. 2009; 55(4):400-4.

8. Brasil. Ministério da Saúde. Conselho Nacional de Saúde. Resolução № 196 de 10 de outubro de 1996. In: Manual operacional para comitês de ética em pesquisa. Brasília: Ministério da Saúde; 2002. p.83-100.

9. Miziara ID. Ethics in scientific publications: the Double copyright problem. Braz. J. Otorhinolaryngol.2010; 76(5):543.

10. Mason PR. Plagiarism in Scientific Publications. J. Infect. Developing Countries. 2009; 3(1):1-4.

11. Conselho Nacional de Desenvolvimento Científico e Tecnológico. Ética e Integridade na prática Científica. Brasília: CNPq; 2011. [capturado 18 out. 2011]. Disponível em: http://memoria.cnpq.br/normas/lei_po_085_11.htm (relatório).

12. Santana CC. O tema da integridade científica nas pós-graduações em saúde no Brasil. Revista Bioética. 2010;18(3): 637-44.

13. Santos LHL. Sobre a integridade ética da pesquisa. São Paulo: FAPESP; 2011.

14. Fontanella BJB, Campos CJG, Turato ER. Critérios de dados na pesquisa clínico qualitativa: Uso de entrevistas não dirigidas de questões abertas por profissionais de saúde. Rev Latino-am Enferm. 2006; 14(5).

15. Minayo MCS. Fase de análise ou tratamento do material. In: $\mathrm{O}$ desafio do conhecimento: pesquisa qualitativa em saúde. 7 ed. São Paulo: Hucitec; 2000.

16. Tauil PL, Guilhem D. Método e ética: Fundamentos indissociáveis no contexto da prática científica. Brasília Med. 2009; 46(Supl 1):19-26.

17. Concil for International Organizations of Medical Sciences. International ethical guidelines for biomedical research involving human subjects. Geneva: CIOMS; 2002- [Capturado em: 18 out 2011]. Disponível em: http:/ /www.cioms.ch/publications/layout_guide2002.pdf

18. Emanuel EJ, Wendler D, Killen J, Grady C. What makes Clinical Research in Developing Countries Ethical? The Benchmarks of Ethical Research. Journal of Infectious Diseases; 2004.

19. European Science Foudation. ORI First World Conference on Research Integrity: Forstering Responsible Research. A Portuguese European Union Presidency and European
Commission Event Initiated and Organized by the European Science Foundation \& the US Office of Research Integrity. Lisboa; 2007. [capturado 18 out. 2011]. Disponível em: http:/ / www.esf.org/index.php?id=4479. (Relatório)

20. Rocha SMM, Ogata MN. Guidelines for Scientific Integrity. Rev Esc Enferm. USP 2004; 38(4): 475-7.

21. Peh WCG, Ng KH. Publication ethics and scientific misconduct. Singapore Med J. 2010; 51(12)908-12.

22. Errami M, Garner H. Are scientists publishing more duplicate papers? An automated search of seven million biomedical abstracts suggests that they are. Nature [online]. 2008. 451. [capturado18 out. 2011]; 397-399. Disponível em: http:/ / www.nature.com/nature/journal/v451/n7177/ full/451397a.html.

23. Fundação de Amparo à pesquisa do Estado de São Paulo. Código de Boas Práticas Científicas [online]. 2011. [capturado18 out. 2011]. Disponível em: http:/ / www.fapesp.br/ boaspraticas/codigo_fapesp0911.pdf.

24. Farthing JM. Publication Misconduct and how editors should respond. COPE. 1999. (relatório)

25. Sharav VH. NY times magazine. Scientific Fraud: Eric Poehlman / Richard Borison. 2006 [capturado em 18 out 2011]. Disponível em http://www.ahrp.org/cms/content/view/370/70/.

26. Wohn Y, Normile D. Korean Cloning Scandal. Prosecutors Allede Elaborate Deception and Missing Funds. Science Magazine [online]. 2006. 312(5776) [capturado 18 out. 2011]; 980-981. Disponível em: http:/ /www.sciencemag. org/content/312/5776/980.full.

\section{CONTRIBUIÇÃO DOS AUTORES}

Patricia Dias Schmitz: revisão de literatura, coleta de dados, redação do artigo. Liliane Lins: orientação da pesquisa, revisão de literatura, interpretação dos resultados, redação do artigo. Marta Menezes: revisão de texto e discussão do método.

\section{CONFLITO DE INTERESSES}

Declarou não haver.

\section{ENDEREÇO PARA CORRESPONDÊNCIA}

Liliane Lins

Rua Frei Henrique, 8

Nazaré - Salvador

CEP 40050-420 — BA

E-mail: lilianelinskusterer@bahiana.edu.br 